Revista Destaques Acadêmicos, Lajeado, v. 10, n. 1, 2018. ISSN 2176-3070

DOI: http://dx.doi.org/10.22410/issn.2176-3070.v10i1a2018.1806

http://www.univates.br/revistas

\title{
ANÁLISE DA BALANÇA DE SERVIÇOS BRASILEIRA NO PERÍODO DE 2005 A 2015
}

\author{
Bruna Kappler ${ }^{1}$, Fernanda Cristina Wiebusch Sindelar ${ }^{2}$
}

Resumo: Este trabalho teve como objetivo analisar as estatísticas da Balança de Serviços brasileira entre 2005 a 2015 e a influência das políticas governamentais sobre o seu desempenho. Para realização da análise, utilizou-se a abordagem quali-quantitativa, através de pesquisa historiográfica, análise documental baseada em publicações de órgãos governamentais e literatura disponível. Os dados secundários foram extraídos de publicações governamentais e sítios da internet. Com o estudo, identificou-se que a Balança de Serviços foi deficitária em todo o período analisado, estando este déficit associado a fatores internos e externos. Além disso, observou-se que o governo vem adotando medidas para aumentar o controle das operações, porém estas foram insuficientes para melhorar o saldo da conta e a competitividade dos serviços nacionais.

Palavras-chave: Comércio Exterior. Balança de Serviços. Políticas Governamentais.

\section{Introdução}

O comércio tem evoluído constantemente, seja no mercado interno de um país ou com o exterior, sobretudo com o acirramento da globalização e maior integração dos mercados. Com a abertura de fronteiras, aumento de negociações e acordos, está cada vez mais fácil e intensa a troca de produtos, seja de mercadorias ou serviços, entre diferentes países. Contudo, embora o Brasil esteja entre as 10 maiores economias mundiais em termos de Produto Interno Bruto (PIB), sua representação é menor se analisarmos os fluxos comerciais entre os países, tanto de bens como de serviços.

Em 2016, o país ocupou a $27^{\mathrm{a}}$ posição em termos das exportações mundiais de mercadorias, sendo responsável por $1 \%$ do total exportado pelos países membros da Organização Mundial do Comércio (OMC) (US\$ 164.377 milhões) e a $26^{a}$ posição em termos de exportações mundiais de serviços, o que também representava apenas $1 \%$ do total negociado pelos países membros

1 Bacharel em Administração pela UNIVATES.

2 Doutora em Ambiente e Desenvolvimento pela UNIVATES. Professora da UNIVATES. 
da OMC (US\$ 47.009 milhões) (WTO, 2017). Em contrapartida, na economia interna, o setor de serviços foi responsável por $75,08 \%$ do valor adicionado gerado nesse mesmo ano (IBGE, 2017).

No período entre 2005 a 2015, as exportações de serviços representaram em média $13,5 \%$ do total de exportações realizadas pelo Brasil, enquanto que as importações de serviços foram cerca de $25,2 \%$ do total de importações do país (UNCTAD, 2015). Em consequência, observa-se que a balança de serviços tem sido deficitária, o que influencia negativamente no resultado da conta de Transações Correntes e no Balanço de Pagamentos.

Dentre as ações governamentais para fomentar o Comércio Exterior de Serviços estão a assinatura do Acordo Geral sobre o Comércio de Serviços (GATS - General Agreement on Trade in Services) e a criação de ferramentas de controle das operações, como a Nomenclatura Brasileira de Serviços (NBS) e o Sistema Integrado de Comércio Exterior de Serviços, Intangíveis e Outras Operações que Produzam Variações no Patrimônio (SISCOSERV). Porém estas ações têm sido insuficientes para melhorar o desempenho da Balança de Serviços. Como os serviços são heterogêneos, estes são influenciados por contextos distintos, sendo o desenvolvimento de estratégias para o seu desenvolvimento também mais difíceis.

Neste sentido, este artigo se propõe a analisar as estatísticas da Balança de Serviços brasileira de 2005 a 2015 e a influência das políticas governamentais, buscando averiguar as principais contas de serviços e as principais políticas governamentais direcionadas a esse setor, como incentivos e barreiras.

Para tanto, este trabalho está organizado em cinco seções além desta introdução. A seguir faz-se uma revisão sobre as características do comércio exterior de serviços. Após apresentam-se os procedimentos metodológicos adotados no desenvolvimento do trabalho. Na quarta seção faz-se uma análise da política brasileira de comércio exterior voltada ao setor de serviços e das principais ações adotadas no período em estudo. Na quinta seção analisa-se o desempenho da Balança de Serviços no Brasil e por fim, são feitas considerações finais.

\section{Comércio exterior de serviços}

O benefício das empresas em comercializar no mercado interno pode ser expandido com a internacionalização das empresas. A abertura do mercado para comércio com o exterior consiste na expansão de possibilidades, materiais e acesso a novos mercados consumidores. A internacionalização de uma empresa promove o desenvolvimento de sua cultura e dos métodos administrativos, aperfeiçoamento da estratégia mercadológica e adequação do produto ao consumidor e, em consequência, aumentam a competitividade do mercado e a qualidade dos bens e serviços prestados. Além disso, para os autores, entre os principais motivos para empresas realizarem o comércio com países 
do exterior estão: a possibilidade de ampliar sua produção e produtividade, com incremento de tecnologias, o melhor emprego da capacidade instalada e sua inserção em novos mercados, aumentando a obtenção de lucros (LOPEZ; GAMA, 2002).

Para atuar no exterior, é necessária uma estratégia governamental e condições que incentivem bons negócios. Segundo Porter (1999), a competitividade de um país depende da capacidade de sua indústria de inovar e aprimorar-se e relata que os fatores econômicos não são fundamentais para tornar o país líder no setor de atuação, e sim a atuação política, combinada com investimentos e principalmente, aumento da produtividade. Essa política de atuação é importante para definir uma estratégia de competitividade do país.

As políticas de comércio exterior referem-se as ações de influência realizadas pelo governo nas operações comerciais, visando garantir o interesse e o bem-estar dos nacionais, por meio de instrumentos institucionais (MELO et al., 1997). Para tanto, o governo deve proporcionar às empresas, condições necessárias para que estas possam atuar tanto no mercado interno quanto no externo, utilizando mecanismos nas áreas administrativas, fiscais, tributárias, de financiamentos, cambial, monetária, de promoção, infraestrutura e logística (LOPEZ; GAMA, 2002).

No Brasil, para fomentar o comércio exterior, a estrutura criada pelo governo baseia-se essencialmente no tripé: Receita Federal do Brasil (RFB) e Banco Central do Brasil (BCB), ambos vinculados ao Ministério da Fazenda (MF), e Secretaria do Comércio Exterior (Secex), vinculada ao Ministério de Desenvolvimento da Indústria e do Comércio Exterior (MDIC). Além disso, buscando auxiliar o governo na formulação da política e as empresas nas operações e promoção dos negócios para fomentar o comércio exterior, ainda é possível contar com o auxílio de duas agências: a Câmera do Comércio Exterior (CAMEX) e a Agência Brasileira de Produção de Exportações e Investimentos (APEX), além de outros órgãos anuentes.

A boa performance destes órgãos é vital para a economia do país, pois se superavitário, o comércio exterior pode contribuir para obtenção de crescimento econômico e de reservas internacionais. Contudo, o setor de serviços conta com peculiaridades e heterogeneidades, o que tem dificultado sua ampliação no setor externo.

Entre os motivos, está o fato das operações de serviços serem caracterizadas por fatores que os diferenciam dos demais bens tais como: a) intangibilidade, uma vez que algo que não podemos tocar ou sentir, por exemplo, o atendimento, a assistência, a garantia, entre outros; b) impossibilidade de armazenagem, visto que seu consumo é simultâneo à produção, não pode ser estocado, sendo a previsão de demanda essencial para utilização de $100 \%$ da capacidade da empresa; c) produção e consumo fisicamente unidos, o que significa que sua produção e entrega é simultânea, com interação do cliente com o fornecedor; d) fácil entrada no mercado, de modo que o volume de 
investimentos, conhecimento e tecnologia pode ser reduzido; e, e) influências externas, como avanços tecnológicos, regulamentação governamental, mudanças econômicas em outros setores e no governo (SCHMENNER, 1999). Em consequência, observa-se a maior dificuldade nas operações e as ações governamentais para desenvolvê-lo.

Além disso, conforme o MDIC, o setor de serviços possui peculiaridades para as operações e as barreiras impostas não são tarifárias - assim como acontece com os bens - e sim, são restrições ao mercado externo, como exemplo:

Restrições a respeito do tipo de presença comercial (por exemplo, somente joint ventures); Requisitos de registro ou de licenciamento discriminatórios; Exigências de nacionalidade e de residência discriminatórios; Tratamento discriminatório que confira vantagens às empresas domésticas em detrimento das empresas estrangeiras; Obrigações de contratação de mão-de-obra local; Aplicação discriminatória de normas técnicas (MDIC, 2016a, texto digital).

Em consequência, entende-se que o trabalho do governo no fomento das operações de serviços é dificultado pela imposição destas barreiras. Além disso, ressalta-se que o estabelecimento de acordos comerciais, dependem diretamente dos parceiros comerciais e da atuação governamental.

Ademais, cabe ainda mencionar que o comércio exterior é diretamente afetado pelo desempenho do câmbio, o qual pode tanto incentivar as exportações como as importações, dependendo da sua cotação. Em outras palavras, a taxa, durante um período, pode explicar aumento ou diminuição do fluxo das operações de compra e venda com o exterior e impactar no mercado interno.

No Brasil, o controle governamental e a concessão de incentivos para ampliação do comércio exterior de serviços são recentes, sendo fundamental o desenvolvimento de estudos que contribuam para o alcance desse objetivo.

\section{Procedimentos metodológicos}

O objetivo desta pesquisa foi exploratório de modo a analisar os resultados da Balança de Serviços e identificar os fatores que influenciaram os resultados. A pesquisa analisou os resultados obtidos entre 2005 a 2015 e o contexto externo no mesmo período, buscando identificar os possíveis fatores que tenham influenciado nesses resultados e as políticas governamentais adotadas.

Quanto as técnicas de coleta, a pesquisa utilizou a abordagem qualiquantitativa. A análise qualitativa ocorreu a partir do exame das políticas de incentivo e barreiras comerciais implementadas pelo governo, enquanto que a análise quantitativa foi baseada em dados secundários divulgados em publicações governamentais e sítios na internet, que apresentam informações 
estatísticas das operações de comércio exterior, taxas de crescimento, principais produtos e mercados, disponíveis no BCB, MDIC, entre outros. Além das fontes internas, também foram coletados dados e informações sobre políticas e estratégias adotadas pelos países junto à OMC e a Conferência das Nações Unidas sobre Comércio e Desenvolvimento (United Nations Conference on Trade and Development - UNCTAD).

Contudo, o controle é frágil e não é homogêneo, dificultando sua mensuração, comparações internacionais e análises de evoluções anuais do comércio exterior de serviços (LÓPEZ; NIEMBRO; RAMOS, 2011). Ademais, muitos serviços estão embutidos nos preços dos produtos, dificultando sua mensuração e deve ser trabalhado com cautela pelo governo.

Também cabe mencionar que nem todas as informações estão disponíveis e desagregadas para o período de análise. Apesar do sistema SISCOSERV disponibilizar em seus relatórios informações detalhadas, estas estão disponíveis somente a partir de 2012, enquanto que para anos anteriores, somente estão disponíveis valores de operações, porém sem a possibilidade de identificar com clareza parceiros comerciais e serviços comercializados, sendo muitos deles obtidos através de outras publicações.

Além disso, ainda se ressalta que os dados fornecidos pela UNCTAD diferem dos oferecidos pelo MDIC no panorama de 2014 e 2015. As informações emitidas pelo MDIC também divergem em publicações de um ano ao outro, entre 2012 a 2015, apresentado dados distintos aos anos anteriores. A alteração é, em média, de um bilhão para mais ou para menos causando distorção dos resultados de importações, exportações e saldo de serviços.

\section{Política Brasileira de Comércio Exterior}

De maneira geral, observa-se que a política de comércio exterior brasileira vem sendo centralizada para o setor de bens, através da assinatura de acordos comerciais, fortalecimento do mercado e da concessão de benefícios fiscais e de crédito. Entre as razões para deixar o setor de serviços em segundo plano está o fato deste possuir produtos não comercializáveis e ser melhor desenvolvido em países desenvolvidos (RIBEIRO, 2011).

Até 2011, o governo brasileiro formalizou relativamente poucos acordos para esse setor, sendo o principal deles o Acordo Geral sobre o Comércio de Serviços (General Agreement on Trade Services - GATS), assinado em 1994 com a ata Final da Rodada Uruguai, estando este em vigor desde janeiro de 1995. O GATS tem por objetivo aumentar investimentos e regular as atividades internacionais de serviços visando a aumentar a transparência e as negociações entre os países participantes (CINTRA, 1999).

Também se destaca o Protocolo de Montevidéu sobre o Comércio de Serviços do MERCOSUL, concluído em 1997, e suas rodadas de negociações. Esse protocolo, somado à posição geopolítica, fez da América do Sul um 
potencial parceiro comercial de serviços. Através dele, foram desenvolvidos "setores como transporte aéreo, serviços bancários, mercados de ações, engenharia, construção, distribuição, franchising, turismo e serviços de telemedicina parecem ter um grande potencial para expandir os seus negócios regionais" (PEREIRA; SENNES; MULDER, 2011, p. 38). Também no Protocolo de Montevidéu é possível identificar políticas de inventivo para: a) Movimento de Pessoas Físicas Prestadoras de Serviços; b) Serviços Financeiros; c) Serviços de Transportes Terrestre e Aquático e d) Serviços de Transporte Aéreo, favorecendo as negociações entre os países membros do Mercosul (BRASIL, 2008).

Em 2005, o governo brasileiro também criou a Secretaria de Comércio e Serviços (SCS), com a responsabilidade de monitorar as operações, auxiliar nas tramitações internacionais e desenvolver o setor (PEREIRA; SENNES; MULDER, 2011). E, em 2011, foi lançado o Portal Brasileiro de Comércio Exterior ${ }^{3}$, pela Secex e MDIC, com o objetivo de instruir empresas internacionalizadas quanto às operações (PORTAL BRASIL, 2011). O sítio possui orientações necessárias para operar em comércio exterior, sendo seu foco alavancar o comércio de bens e investimentos, mas também disponibiliza informações sobre as operações de serviços, como o panorama anual, estatísticas e o perfil brasileiro de operações em serviços.

Adicionalmente, para fazer o registro das operações de comércio exterior de serviços e de intangíveis o governo lançou em 2012, o Sistema Integrado de Comércio Exterior de Serviços, Intangíveis e Outras Operações que Produzam Variações no Patrimônio (SISCOSERV). O objetivo do sistema é "o combate à sonegação de impostos e o aumento do controle de informações de transações com o exterior" (PORTAL BRASIL, 2012a, texto digital). Ele também auxilia no registro, mensuração e monitoramento de operações de pessoas físicas e jurídicas, de modo a contribuir com o aperfeiçoamento da política de comércio exterior de serviços (PORTAL BRASIL, 2012b). Daltson e Oliveira (2015) reiteram o pioneirismo do Brasil com a adoção do sistema e a eficiência da captação de dados e fornecimento de informações à sociedade.

Neste mesmo ano, também se instituiu o Decreto Presidencial $\mathrm{n}^{\circ}$ 7.708, de 02 de abril, oficializando a lei $\mathrm{n}^{\mathrm{o}}$ 12.546, de 14 de dezembro de 2011, que teve por objetivo definir a Nomenclatura Brasileira de Serviços (NBS) e suas notas explicativas (BCB, 2016). A NBS define códigos para os serviços e intangíveis, garantindo maior confiabilidade das informações, assim como para a fiscalização e apreciação das políticas governamentais.

3 Atualmente, ao acessar sítio do novo Portal Brasileiro de Comércio Exterior, fornecido pelo Portal na reportagem, percebe-se que o mesmo foi atualizado para www.investexportbrasil. gov.br, ativo até na data de acesso. 
A NBS é o classificador nacional para a identificação dos serviços e intangíveis como Produtos viabiliza a adequada elaboração, fiscalização e avaliação de políticas públicas de forma integrada. Visando a competitividade do setor, propicia a harmonização de ações voltadas ao fomento empreendedor, à tributação, às compras públicas, ao comércio exterior, entre outras (INVEST EXPORT BRASIL, 2016, texto digital).

Assim, percebe-se que no período recente, o governo tem despendido maior atenção às operações de serviços. A utilização da NBS e do SISCOSERV trouxeram, a partir de 2012, maior controle na apuração dos dados e formulação das estatísticas do comércio exterior de serviços. Com a implantação de ambos, as operações tornaram-se mais rígidas e monitoradas pelo governo, impossibilitando e/ou minimizando a realização de fraudes, assim como, facilitaram o acompanhando do volume das negociações em cada setor dos serviços.

Contudo, em relação a política de incentivos e barreiras para o setor se tem poucas informações claras, exceto quando se aclara as linhas de financiamento. No Guia Básico para Exportação de Serviços de 2014, emitido pela RFB com apoio do MDIC, no qual destacam-se dois tipos de fomento e benefícios para exportação de serviços: Incentivos Financeiros e Incentivos Fiscais. Entre os incentivos financeiros, estão os incentivos de crédito que o governo fornece aos financiamentos à exportação, oferecendo ao vendedor a oportunidade de subsídio às operações, como adiantamentos de contrato de câmbio sem tarifas, auxílio financeiro para produção do serviço (investimentos em tecnologia, desenvolvimento, pesquisa e para pagamento das importações), além de fornecer garantias ao exportador em casos de instabilidade política ou econômica, fornecimento de taxas de juros equivalentes às internacionais. Cabe às empresas encontrar a fonte de subsídio que se enquadra com as necessidades, utilizando os incentivos disponibilizados na política governamental (MDIC, 2014a, p. 28).

Já entre os incentivos fiscais para a exportação de serviços tem-se a isenção de tributação de PIS/PASEP, COFINS, ISS (exceto para aqueles realizados no Brasil). Já tributos como IRPJ e CSLL incidem normalmente, conforme enquadramento da empresa. Além disso, há dois regimes especiais de tributação, um deles incentivando a exportação de tecnologia de informação e o segundo com benefícios para aquisição de bens de capital por empresas exportadoras (MDIC, 2014a, p. 28).

Embora os incentivos mencionados representem as tributações atuais incidentes sobre o operador de comércio exterior de serviços, percebe-se que estes não representam volume ou atratividade para fomentar o setor. Além disso, observa-se que estes incentivos são adaptações da política desenvolvida para o setor bens, carecendo de detalhes e adaptações para o setor de serviços. 
Adicionalmente, a Confederação Nacional da Industria (CNI), ainda reitera que, além de elevados, ocorrem distorções nos cálculos de impostos incidentes sobre a importação de serviços, desestimulado sua ocorrência, em especial na importação de tecnologia, de modo que as fábricas acabam por produzir localmente, com acesso restrito aos recursos externos. Em consequência, uma política que tem por objetivo reduzir a quantidade de importações pode gerar resultados contraditórios, entre eles a falta de competitividade da indústria que necessita de tecnologia importada (CNI, 2013).

Outra barreira comercial está associada ao quesito de expatriação dos funcionários para prestar serviços no exterior. A legislação em vigor (lei $\mathrm{n}^{\mathrm{o}} 7.064 / 1982$ e de sua extensão promovida pela lei $\mathrm{n}^{\circ} 11.962 / 2009$ ) utiliza o princípio da territorialidade para processos burocráticos de contratação de funcionários no exterior, ou seja, caso a empresa queira utilizar seus próprios funcionários, terá que contratá-los no Brasil (conforme leis vigentes no país) e realizar uma contratação no exterior (conforme as leis do outro país). Para autorização prévia, o Ministério do Trabalho deve ser acionado e as divergências devem ser resolvidas em tribunais brasileiros. Outros fatores são processos rescisórios e fundo de garantia, que aumentam os custos e a burocracia realizada pela empresa. A contratação de funcionários do exterior é inevitável, para garantir a competitividade da empresa. Assim, uma alteração nas leis trabalhistas para prestação de serviços no exterior é urgente e necessária para alavancar o setor de comércio exterior de serviços (LIMA, 2016).

De maneira complementar, Daltson e Oliveira (2015, p. 58) ainda salientam que "nosso país é criativo, mas carente de educação e, provavelmente, por isso, apresente números tão fracos em sua Balança de Serviços".

Em síntese, observa-se que o governo brasileiro precisa reavaliar sua política e disponibilizar informações, de maneira mais centralizada e clara, para as empresas que desejarem internacionalizar-se neste setor, além de ampliar os incentivos concedidos e reduzir as barreiras incidentes para ampliar o comércio exterior de serviços no Brasil.

\section{Desempenho do Comércio Exterior de Serviços}

No período em análise neste estudo, observa-se em média, um crescimento do volume (em dólar) das operações de exportações e importações de serviços, com maior destaque das importações que aumentaram significativamente e ampliaram o déficit da Balança de Serviços. Além disso, analisando os dados anuais, observa-se a existência de crescimento entre 2005 a 2008, instabilidade no ano de 2009 (reflexo da crise da bolha imobiliária americana), e o retorno do crescimento entre 2010 a 2014, sendo 2014 o ano com maior volume importado, atingindo o montante de US $\$ 88.072$ milhões, o que corresponde a um crescimento de $276 \%$ se comparado a 2005. Já as exportações 
no mesmo período cresceram $147 \%$. Essa diferença influenciou negativamente o saldo da Balança de Serviços, que a cada ano tornou-se mais negativa, atingindo a marca de US\$ -48.107 milhões em 2014 (GRÁFICO 1).

Gráfico 1 - Balança de Serviços brasileira de 2005 a 2015, em milhões de dólares

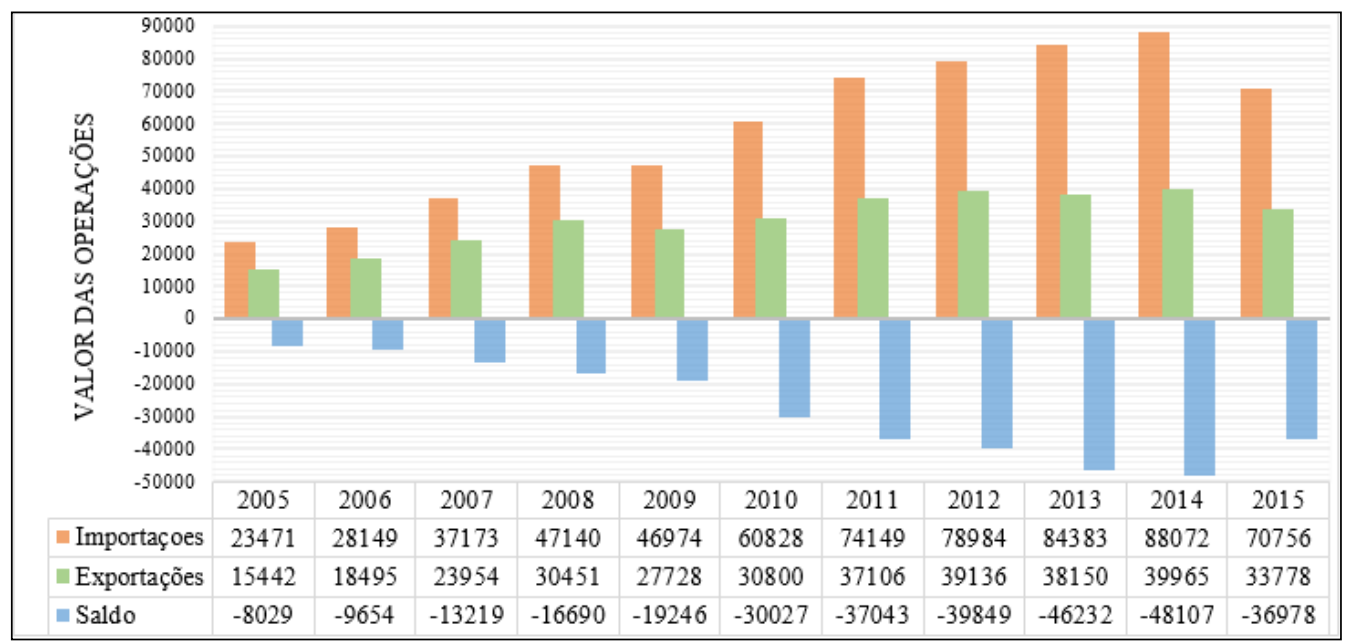

Fonte: Elaborado pelos Autores com base em (UNCTAD, 2015, texto digital).

Já em 2015 foi registrada uma redução das operações. As importações de serviços tiveram um retrocesso de $-19,6 \%$, enquanto as exportações retrocederam $-15,4 \%$ em volume de dólar, e o déficit apurado foi de US $\$ 36.978$ milhões. Entre as razões para a queda no volume das operações, salienta-se a crise política interna brasileira e a contração da demanda, a queda nos preços de commodities, a volatilidade dos mercados financeiros, fuga de capitais, entre outros (CINTRA, 2016).

A UNCTAD (2016) também acrescenta que a queda nos valores operacionais de serviços pode ser atribuída a depreciação de moedas das principais potências comerciais na comparação com o dólar, como exemplo, cita a União Europeia: cujas exportações, em dólares, caíram -10\%, contudo se considerado em termos de Euros, apresentaram um crescimento de 8\%. Assim, considerando o fator dólar, percebe-se que o dólar atingiu a marca de $\mathrm{R} \$ 3,89$ em 2015 (ACS SERVIÇOS, 2016). Esse processo reduziu o valor das operações em dólar, gerando resultados menores que o ano anterior, embora em valores reais o valor comercializado tenha sido o mesmo.

A Tabela 1 apresenta os valores discriminados para as principais rubricas por tipo de serviço. De maneira geral, observa-se que os déficits estão presentes na maioria das contas em todos os anos, prejudicando o saldo da Balança de Serviços e o desempenho da economia. Em 2015, apenas três contas apresentaram um resultado positivo: serviços de manutenção e reparo, 
construção e outros serviços de negócio, inclusive arquitetura e engenharia. Em todas as demais, o país importou um volume maior de serviços do que exportou.

Tabela 1 - Balança de Serviços brasileira, discriminada por serviços, de 2005 a 2015, em milhões de dólares

\begin{tabular}{|c|c|c|c|c|c|c|c|c|c|c|c|}
\hline Discriminação & 2005 & 2006 & 2007 & 2008 & 2009 & 2010 & 2011 & 2012 & 2013 & 2014 & 2015 \\
\hline $\begin{array}{l}\text { Serviços de manufatura sobre } \\
\text { insumos físicos pertencentes a outros }\end{array}$ & - & - & - & - & - & - & - & - & - & 14 & -2 \\
\hline Serviços de manutenção e reparo & 2 & 5 & 2 & 4 & 13 & 6 & -9 & -11 & -27 & 160 & 256 \\
\hline Transportes & -1953 & -3123 & -4378 & -4996 & -3924 & -6138 & -7962 & -8398 & -9376 & -8697 & -5664 \\
\hline Passageiros & -878 & -1476 & -1893 & -1983 & -1668 & -2657 & -3531 & -3723 & -3949 & -3870 & -2589 \\
\hline Fretes & -866 & -1136 & -1552 & -2599 & -1740 & -2625 & -3387 & -3437 & -3859 & -3694 & -2551 \\
\hline Outros serviços de transportes & -209 & -511 & -934 & -413 & -516 & -856 & -1044 & -1237 & -1568 & -1133 & -524 \\
\hline Viagens & -858 & -1448 & -3258 & -5177 & -5594 & -10704 & -14707 & -15661 & -18554 & -18724 & -11513 \\
\hline Negócios & -826 & -717 & -886 & -2095 & -1350 & -2427 & -2889 & -2917 & -3027 & -3701 & -1591 \\
\hline Pessoais & -32 & -731 & -2373 & -3082 & -4244 & -8277 & -11818 & -12743 & -15527 & -15023 & -9922 \\
\hline Construção & 8 & 18 & 12 & 14 & 11 & - & - & - & - & 267 & 46 \\
\hline Seguros & -568 & -430 & -766 & -837 & -1442 & -1113 & -1212 & -994 & -1076 & -783 & -333 \\
\hline Serviços financeiros & -230 & -110 & 283 & 93 & -42 & 208 & 843 & 774 & 1308 & 184 & -282 \\
\hline Serviços de propriedade intelectual & -1303 & -1513 & -1940 & -2232 & -2078 & -3036 & -3447 & -3922 & -4199 & -5548 & -4669 \\
\hline $\begin{array}{l}\text { Telecomunicação, computação e } \\
\text { informações }\end{array}$ & -1502 & -1811 & -1945 & -2442 & -2422 & -3164 & -3714 & -4025 & -4501 & -2224 & -1768 \\
\hline Aluguel de equipamentos & -4130 & -4887 & -5771 & -7808 & -9393 & -13718 & -16682 & -18736 & -19056 & -22629 & -21532 \\
\hline $\begin{array}{l}\text { Outros serviços de negócio, inclusive } \\
\text { arquitetura e engenharia }\end{array}$ & 3801 & 4790 & 6370 & 8420 & 7591 & 6969 & 8731 & 9473 & 8326 & 12651 & 10247 \\
\hline $\begin{array}{l}\text { Serviços culturais, pessoais e } \\
\text { recreativos }\end{array}$ & -396 & -452 & -578 & -783 & -878 & 2022 & 2384 & 2741 & 2443 & -1541 & -659 \\
\hline Serviços governamentais & -755 & -450 & -1134 & -1116 & -1416 & -1488 & -1390 & -1410 & -1661 & -1238 & -1045 \\
\hline Total de Serviços & -7883 & -9410 & -13103 & -16861 & -19574 & -30156 & -37166 & -40168 & -46372 & -48107 & -36919 \\
\hline
\end{tabular}

Fonte: Elaborado pela Autora com base em (BCB, 2016, texto digital).

Já analisando os resultados individualmente podemos destacar o desempenho da conta aluguel de equipamentos. Em 2005, o déficit apurado foi de US $\$-4,1$ bilhões; já em 2015 alcançou o montante de US\$ -21,5 bilhões, sendo esta a conta com maior déficit em 2015. Essa rubrica mostrou-se deficitária devido à baixa tecnologia e a divergência do parque fabril do Brasil, como exemplo para a extração de petróleo, já que o Brasil não possui maquinário, acaba importando o serviço de aluguéis.

Ademais, o país não exporta nada associado a isso, evidenciando a deficiência no setor. A falta de especialização brasileira no setor acaba gerando a necessidade de compra do exterior, causando, assim, o maior déficit da conta de serviços brasileira, representando $58 \%$ do déficit da Balança de Serviços em 2015. Em contrapartida, a CNI (2013) reitera o quanto a entrada de tecnologia externa possui entraves operacionais como altos impostos, gerados pelo protecionismo político, o fato é que mesmo com essa barreira comercial, 
o serviço de aluguel de equipamentos ainda é deficitário, significando representatividade nas importações.

Entre os principais fornecedores de equipamentos ao país estão os Países Baixos, mais precisamente a Holanda, que é responsável por contratos no aluguel de equipamentos para a Petrobrás, fornecendo maquinário para a produção de petróleo (PEREIRA, 2014). Além disso, Stefano (2016) menciona que a empresa Shell, grande rede petrolífera, é anglo-holandesa, seguramente realizando aquisições no próprio país de origem, mesmo depois de instalada no Brasil. Em 2015, 86\% das importações de serviços realizadas nos países baixos foram destinados à essa rubrica. Além disso, os Estados Unidos também é um importante prestador desse serviço ao país (em torno de $23 \%$ do valor total).

Outra conta que contribuiu significativamente para o resultado negativo é a conta de viagens. Analisando a conta percebe-se que um valor considerável da conta está em viagens pessoais (US\$ -10 bilhões em 2015) e não em viagens de negócios (US\$ -1,5 bilhões em 2015). Assim, o déficit na conta de viagens internacionais pode ser explicado pelo crescimento e consolidação da classe média na última década, que foi acompanhado pelo aumento do número de turistas brasileiros no exterior (MDIC, 2013), visto que o valor despendido com elas cresceu ano após ano ao longo do período analisado com exceção do final de 2014 e 2015, reflexo da recessão econômica brasileira.

Além disso, embora o governo brasileiro tenha desenvolvido políticas de incentivos ao turismo em 2014 e anos anteriores, com investimentos em infraestrutura, aeroportos, telecomunicações, entre outros, devido a realização da Copa do Mundo de futebol (PORTAL DA COPA, 2015), não é possível identificar alterações positivas nos resultados desta conta em específico, visto que as importações de turismo corresponderam a US\$ 6 bilhões em 2013 e 2014, enquanto as exportações foram de US\$ 25 bilhões, não alterando o saldo da rubrica (déficit de US\$ 18 bilhões) em cada ano (ano anterior e durante a realização do campeonato). Por outro lado, em 2015 observou-se uma redução do déficit da conta de viagens, podendo ser um reflexo do aumento da visibilidade do país ou da perda de poder de compra da população de maneira geral, que sofreu com a desvalorização do real frente a outras moedas e acabou reduzindo a quantidade de viagens realizadas para turismo, assim como da crise econômica interna.

Para Brito, Pereira e Baptista (2015), devido as características que o país possui como o clima tropical, a grande extensão litorânea e os biomas como o Pantanal e a Amazônia, o Brasil poderia desenvolver o comércio exterior de serviços a partir do setor de turismo, porém não o incentiva. Para reduzir os déficits na conta viagens internacionais, o país deveria promover a geração de receita com a visita de estrangeiros ao país, ampliando o mercado dos serviços de alojamento e alimentação brasileiro, através de políticas públicas que promovam a competitividade do turismo no país, como a infraestrutura de portos e aeroportos (PEREIRA, 2014, p. 93). 
Por outro lado, o que se observou em 2015 foi a adoção de política governamental para reduzir a quantidade de importações de viagens (brasileiros viajando ao exterior), com a restituição da cobrança de imposto de $25 \%$ de Imposto de Renda sobre remessas ao exterior para prestação de serviços, desta forma, agências de turismo repassaram o aumento ao consumidor final. A medida entrou em vigor em janeiro de 2016, não impactando nos resultados desta análise, porém é considerada uma medida governamental para reduzir o déficit da rubrica e incentivar as viagens nacionais. "O setor de turismo tinha isenção dessa cobrança com base no artigo 60 da Lei 12.249 de 2010, que estipulava o prazo de $1^{\circ}$ de janeiro de 2011 a 31 de dezembro de 2015 para a alíquota zero" (CACIOLI, 2016, texto digital), sendo um dos fatores que justificam os maiores déficits da rubrica de viagens no período analisado.

A conta de Transportes também teve uma participação relevante, sendo responsável por quase $15 \%$ do déficit da Balança de Serviços. As contas de passageiros e fretes ocupam igual resultado dentro da rubrica e ambas apresentam histórico deficitário crescente, com exceção de 2009 e 2015, onde os resultados foram alterados por fatores externos, como a crise da bolha imobiliária e queda no preço de commodities em 2015. O déficit demonstra que o país possui deficiência no serviço de transporte interno e na exportação do setor, sendo que a rubrica atingiu o valor de $-5,6$ bilhões de dólares em 2015. Além disso, o desempenho negativo da conta de transportes pode ser relacionado à performance do país como exportador de commodities agrícolas e minerais, sendo a rubrica um serviço secundário à exportação de bens (MDIC, 2013).

A rubrica de Serviços de propriedade intelectual historicamente já apresentava um dos maiores déficits da Balança de Serviços entre 1992 a 2001, sendo US $\$-7,3$ bilhões associados royalties e licenças (PEREIRA, 2002). No ano de 2005, a conta estava com US $\$ 1,3$ bilhões negativos e atingiu o patamar de US\$ - 5,5 bilhões em 2014. E, apesar de 2015 ter apresentado uma redução no volume, o déficit ainda foi de US $\$-4,6$ bilhões. Além disso, os Serviços de direitos de autor estão presentes entre os três principais itens importados dos Estados Unidos nos últimos quatro anos e representam 17,3\% das operações de importação realizadas dos Estados Unidos (MDIC, 2013).

Por outro lado, a rubrica Outros serviços de negócio, inclusive arquitetura e engenharia foi a principal rubrica a obter superávit. Em 2005, a conta já apresentava um superávit de US\$ 3,8 bilhões, com crescimento de $230 \%$ até 2014, quando a conta atingiu o auge de US\$12,6 bilhões. Em 2015, apesar de ter apresentado uma queda, apresentou um superávit de US $\$ 10,2$ bilhões. Por isso, essa é a principal conta que contribui para minimizar os déficits apurados na Balança de Serviços. Conforme o Panorama de Comércio Exterior de Serviços (MDIC, 2013) destacam-se os serviços de arquitetura, engenharia e outros serviços técnicos e manutenção e instalação de escritórios e aluguel de imóveis, além de honorários de profissionais liberais. O superávit da conta dá indícios de profissionalização do mercado interno brasileiro que 
começa a exportar conhecimento. Assim, torna-se uma oportunidade, porém ainda se observa a existência de barreiras que dificultam ou impedem algumas atividades, entre elas, cita-se as leis trabalhistas, controles das operações de construção e redução da burocracia, conforme já mencionado anteriormente.

Já a rubrica Construção, que apresentou um superávit de US\$ 62 milhões entre 2005 a 2009, não apresentou nenhum registro entre 2010 e 2013. Para essa falta de informações, mesmo com a obrigatoriedade do SISCOSERV a partir de 2012, há duas explicações possíveis: a falta de lançamento de dados devido a denúncias de corrupção das construtoras ou o lançamento das contas nos serviços de negócio, arquitetura e engenharia, cujo resultado foi superavitário. Por outro lado, no Panorama de Serviços de 2012 (MDIC, 2013) é possível encontrar a informação de atividades na ordem de US\$ 10 milhões no setor de construção, mas não constante no relatório publicado pelo BCB. Já em 2014 houve novamente o registro de superávit no montante de US\$267 milhões em 2014 e US\$ 46 milhões em 2015.

Vários autores destacam o quanto o mercado da construção possui oportunidades para brasileiros que querem exportar serviços, para isso, mesclam informações com a consultoria em engenharia, aqui separada em duas contas distintas. Porém, a balança comercial apresenta falha nos registros das operações de construção, o que se torna um fator contraditório.

Para Pereira, Sennes e Mulder (2011), a construção civil também impulsiona a exportação de bens, além de destacarem a existência de empresas brasileiras de grande porte atuando no cenário mundial exportando engenharia e construção. "Em 2007, três empresas brasileiras estavam entre as 225 maiores exportadoras de construção do mundo: Norberto Odebrecht $\left(21^{\mathrm{a}}\right)$, Construtora Andrade Gutierrez $\left(82^{\mathrm{a}}\right)$ e Camargo Correa Construção e Comércio $\left(203^{\mathrm{a}}\right)^{\prime \prime}$ (ENR RERCORD ENGINEERING NEWS; 2007, apud PEREIRA; SENNES; MULDER, 2011, p. 49). Por outro lado, diversas empresas do setor estão envolvidas em escândalos de corrupção denunciadas recentemente, o que pode vir a prejudicar as operações do setor ${ }^{4}$.

Já em relação as demais contas do Balanço de serviços observou-se que estas possuem menor representatividade, não causando um considerável impacto sobre a apuração do resultado, embora o resultado apurado da maioria delas também tenha sido deficitário ao longo do período analisado.

4 Por exemplo, as Construtoras Andrade Gutierrez e Odebrecht podem ser investigadas nos Estados Unidos por suborno a funcionários públicos, lavagem de dinheiro, sonegação e outras fraudes (STEFANO, 2016). Guimarães (2016) traz a lista dos principais países latino americanos (Peru, Argentina, Venezuela), envolvidos com a Lava Jato, que vincula as construtoras em obras do exterior com a Petrobrás, em todas mencionando pagamento de propina a funcionários públicos. As operações de delação do Lava Jato impactaram a política e economia do país a partir de 2015, afetando, principalmente as maiores empresas brasileiras que operam no comércio exterior de serviços. 
Em resumo, as contas de serviços apresentaram, de modo geral, histórico deficitário, sendo os maiores déficits associados a conta de arrendamento mercantil de máquinas e equipamentos, a conta de viagens e serviços de propriedade intelectual, sugerindo a falta de tecnologia e infraestrutura do país. O superávit apresentado por poucas contas não foi suficiente para equilibrar os resultados da Balança de Serviços. Entre 2005 a 2008, a Balança cresceu em seu volume de operações, em importações mais que em exportações e, consequentemente, maior o déficit anual. Em 2009, percebe-se os impactos da crise financeira de 2008 com uma leve estagnação nos serviços, enquanto os bens sofrem maior impacto. Já no período entre 2010 até 2014, a Balança de Serviços seguiu no mesmo ritmo anterior, com aumento gradativo das operações, em especial das importações, e resultado deficitário. E, no ano de 2015 houve a redução das operações registradas na Balança de Serviços, minimizando o déficit. Entre os fatores, cita-se a crise política brasileira, mas também a desaceleração da China, queda nos preços de commodities, volatilidade dos mercados financeiros, entre outros.

Assim, verifica-se que o governo brasileiro precisa desenvolver mais o setor de comércio exterior de serviços, para poder aumentar a participação deste no comércio internacional. Como, por exemplo, a alteração das leis trabalhistas, possibilitando a geração de empregos no exterior com benefícios às empresas e ao funcionário e viabilizando as operações. A falta de auxílio governamental quanto a definição das leis trabalhistas e a necessidade de contratação de funcionários do exterior devido a burocracia e altos custos rescisórios são fatores que travam as operações e o possível superávit do setor de serviços. Ainda, uma reformulação de benefícios fiscais e financeiros, com redução da burocracia nas operações, traria resultados positivos.

Além disso, o governo não empreendeu ações que resultassem melhores números no saldo da balança comercial. O período em que o governo implantou o sistema SISCOSERV (2012 a 2015) apresentou os maiores déficits dos últimos 11 anos. Sendo que, desde a sua implantação, a única mudança ocorrida foi a retração econômica de 2015 mencionada por Cintra (2016). Mesmo tendo avançado no controle das operações, não há sinais de que o sistema tenha sido utilizado para determinar estratégias e evoluções no setor. Ademais, os relatórios do sistema não apresentam dados consolidados sobre os principais produtos, destacando com mais ênfase as relações com os parceiros comerciais.

Com os resultados desta análise e avaliação do contexto do comércio exterior de serviços, é possível identificar melhorias para desenvolver e fomentar o setor para, consequentemente, obter superávit. O governo possui estratégia para o comércio de bens, não considerando o setor de serviços, que acaba negativo a ponto de afetar o superávit dos bens. Para que os serviços se desenvolvam e atinjam um equilíbrio das importações com as exportações, é necessário maior engajamento governamental, reestruturação da cultura 
nacional, enfatizando os serviços para que se tornem mais eficientes, empenho na mudança de leis, no acesso à informação e nas estatísticas do setor.

\section{Considerações Finais}

Com o desenvolvimento deste estudo, cujo objetivo foi a analisar as estatísticas da Balança de Serviços de 2005 a 2015 e a influência das políticas governamentais, constatou-se que o setor externo de serviços não possui a mesma relevância que o setor de bens para o Brasil. No período 2005 a 2015, o comércio de bens representou $85 \%$ das negociações internacionais, enquanto que o setor de serviços respondeu por apenas $15 \%$ do volume de exportações do país.

Entre os fatores que influenciaram esse desempenho tem-se a influência de fatores externos tais como o desempenho econômico dos países parceiros (períodos de crescimento econômico x crises) e alterações cambiais devido alterações nos fluxos financeiros internacionais, os quais em alguns momentos demandaram adoção de medidas corretivas por parte do governo brasileiro para evitar uma valorização ou desvalorização em larga medida do Real.

Além disso, outro fator foi o insuficiente número de políticas governamentais destinadas ao setor. As ações desenvolvidas pelo governo foram incapazes de melhorar o saldo da Balança de Serviços. O sistema SISCOSERV, implantado em 2012 não foi eficiente no alcance de seus objetivos, apresenta informações que são divergentes de outras fontes e seus resultados não serviram como referência para a elaboração de nenhuma estratégia destinada ao setor de serviços até 2015. Embora tenha se identificado que o volume de exportaç̃oes de serviços aumentou ano a ano, assim como sua participação no saldo do comércio internacional do país, o volume de importações de serviços cresceu em magnitude superior, aumentando também o déficit na Balança de Serviços.

Diante desse cenário, o próprio Ministério da Indústria, Comércio Exterior e Serviços reconhece a importância dos serviços na economia brasileira, assumindo que são necessárias ações para que o mesmo se torne competitivo. Neste sentido, verificou-se que o Brasil tem diversas oportunidades para desenvolver-se. Entre os setores potenciais de desenvolvimento estão o setor da construção civil, devido a existência de construtoras nacionais de grande porte com participação no cenário internacional e os setores de arquitetura, engenharia e serviços de profissionais liberais, porém ainda assim, parecem existir barreiras e/ou dificuldades que impedem o Brasil em especializar-se e desenvolvê-los para que ocorre a ampliação das exportações desses serviços. Por outro lado, o déficit no setor de aluguel de máquinas e equipamentos também demonstra que o país não possui indústria nacional forte e necessita de tecnologia para desenvolvê-la, assim como ocorre no setor de telecomunicações, computação e informações. No setor de turismo, embora o país apresente características 
naturais que contribuem para o fomento do setor, também se observou que o desenvolvimento de políticas, como o apoio ao desenvolvimento de eventos esportivos, foi insuficiente para a obtenção de superávits, sendo influenciados em parte pela piora do desempenho econômico no período mais recente. $\mathrm{Na}$ conta de transportes, a deficiência da infraestrutura interna e o volume brasileiro de exportação de commodities, torna o serviço uma venda agregada e secundária à exportação do bem.

Embora o país conceda incentivos financeiros através de programas de financiamentos aplicados ao comércio exterior de bens e adaptados aos serviços, não há tratamento especial para incentivar o setor de serviços. Ademais, há de se mencionar a burocracia necessária para realização de um financiamento, de modo que o sistema de financiamentos ao mesmo tempo em que é um incentivo, às vezes torna-se um empecilho para as empresas. E, por outro lado, no quesito fiscal, não há isenções nem mesmo benefícios. As exportações seguem a linha dos bens e as importações pagam altas taxas e impostos para nacionalização. $\mathrm{O}$ sistema fiscal é um sistema de proteção interna, possibilitando as exportações, mas sem incentivá-las, enquanto protege a entrada de serviços externos com a taxação e dificuldade no acesso à informação.

Os incentivos governamentais internos são no âmbito da capacitação e inovação. A evolução apresentada pelo governo esteve associada ao aumento do controle das operações e das informações, com o SISCOSERV e NBS. Há programas de auxílio ao serviço nacional para capacitar-se e adaptar-se à exportação. Não há incentivo aos serviços tecnológicos, nem mesmo aos que geram o maior déficit da balança comercial. $\mathrm{O}$ governo realizou ações para desenvolver o setor interno e, a longo prazo, os resultados poderão, ou não, serem vistos no setor externo.

Com os resultados desta análise e avaliação do contexto do comércio exterior de serviços, é possível identificar que se fazem necessárias melhorias para desenvolver e fomentar o setor para, consequentemente, reduzir o déficit ou alcançar o superávit. Para que os serviços se desenvolvam e atinjam um equilíbrio das importações com as exportações, é necessário maior engajamento governamental, reestruturação da cultura nacional, enfatizando os serviços para que se tornem mais eficientes, empenho na mudança de leis, no acesso à informação e nas estatísticas do setor.

Em síntese, os resultados negativos da balança comercial de serviços possuem um contexto que os influencia e não permite a geração de resultados positivos. No contexto avaliado, a política governamental é capaz de realizar alterações que possibilitem evoluções e suas ações atuais estão progredindo, porém ainda não influenciam a balança comercial de serviços e não alcançam resultados superavitários.

O desenvolvimento interno proporciona desenvolvimento de serviços. Investimentos em infraestrutura de portos e aeroportos, repercutem em aumento de turismos e transportes de carga internacional, auxiliando a reduzir 
o déficit de duas contas importantes. Para reduzir o maior déficit de serviços, o governo pode implantar políticas de incentivo à tecnologia nacional e produção nacional de máquinas e equipamentos que atualmente são alugados. O setor de construção civil necessita de registros por parte governamental, sendo o primeiro passo para desenvolvê-lo, seguido da reformulação das leis trabalhistas, para fomentar o setor.

Ademais, como estratégia, é fundamental aplicar políticas de capacitação, formando profissionais aptos para trabalhar com comércio exterior e, principalmente, com capacidade de fomentar setores estagnados na balança comercial, como manufaturas, manutenção e reparo, serviços financeiros, culturais, pessoais e de saúde. Essas contas, atualmente, estão em níveis de estagnação e com o incentivo adequado é possível especializar-se e suprir necessidades de importação que o Brasil possui atualmente.

Com a análise detalhada das operações de comércio exterior de serviços e seu contexto pode-se concluir a atual situação das rubricas que a compõem e apresentar políticas de desenvolvimento dos resultados negativos. Com base nos dados e estatísticas percebe-se a situação deficitária do país e as análises do contexto que influenciam os resultados identificam debilidades na estratégia governamental e possíveis soluções para melhoria dos resultados. Com utilidade para conhecimento atualizado dos mecanismos e resultados do comércio exterior de serviços, este trabalho também informa quanto a dificuldades operacionais que podem interferir nas operações de serviço internacionais.

\section{Referências}

ACS SERVIÇOS. Dólar. 2016.Texto Digital. Disponível em: http:/ /economia. acspservicos.com.br/indicadores_iegv/iegv_dolar.html. Acesso em 08/09/2016.

BANCO CENTRAL DO BRASIL (BCB). Série histórica do Balanço de Pagamentos - $\sigma^{a}$ edição do Manual de Balanço de Pagamentos e Posição de Investimento Internacional (BPM6). Disponível em: https://www.bcb.gov.br/htms/infecon/ Seriehist_bpm6.asp. Acesso em 23/09/2016.

BRITO, Kawane; PEREIRA, Paula Agda; BAPTISTA; Jose Abel. The services exports in brazilian economy. Congresso Nacional de Excelência em Gestão. 2015. Disponível em: http:/ / www.inovarse.org/filebrowser/download/7934. Acesso em 05/09/2016.

CACIOLI, Natália. Mudança em IR de remessas ao exterior encarece viagens e provoca dúvidas. Estadão. 2016. Disponível em: http:/ /economia.estadao.com.br/ noticias/geral,mudanca-em-ir-de-remessas-ao-exterior-encarece-viagens-e-provocaduvidas,10000013259. Acesso em 14/11/2016. 
CINTRA, Marcos Antônio Macedo. A participação brasileira em negociações multilaterais e regionais sobre serviços financeiros. Rev. bras. polít. int. [online], n. 1, v. $42,1999$.

A crise econômica mundial e a quarta Revolução Industrial. 2016. Disponível em: http:/ / www.cartacapital.com.br/blogs/blog-do-grri/a-criseeconomica-mundial-e-a-quarta-revolucao-industrial. Acesso em 23/09/2016.

CONFEDERAÇÃO NACIONAL DA INDÚSTRIA (CNI). Tributação Sobre Importação de Serviços: Impactos, Casos e Recomendações de Políticas. - Brasília. CNI. 2013. Disponível em: tributaosobreimportaaodeservios-impactoscasoserecomend aesdepolticas.pdf Acesso em 05/09/2016.

DALSTON, Cesar Olivier; OLIVEIRA, Vivian. Comércio exterior de serviços: SISCOSERV e fretes. Revista Brasileira de Comércio Exterior, n. 125, 2015. Disponível em: http://www.funcex.org.br/publicacoes/rbce/material/rbce/125_CODVO.pdf. Acesso em 29/08/2016.

GUIMARÃES, Thiago; BBC. 'Lava Jato exportação': O que se sabe até agora sobre conexões internacionais do esquema de corrupção. 2016. Disponível em: http:/ / www.bbc.com/portuguese/brasil/2016/05/160505_lavajato_exterior_tg, acesso em 26/09/2016.

INSTITUTO BRASILEIRO DE GEOGRAFIA E ESTATÍSTICA (IBGE). Contas Nacionais. Disponível em: https:/ / www.ibge.gov.br/estatisticas-novoportal/ economicas/contas-nacionais.html. Acesso em:01/04/17.

INVEST EXPORT BRASIL. NBS e NEBS, 2016. Disponível em: http:/ / www. investexportbrasil.gov.br/nbs-e-nebs. Acesso em 20/09/2016.

LIMA, Christina Aires Correa. A questão da expatriação para prestação de serviços em empresas brasileiras no exterior. Revista Brasileira de Comércio Exterior, n. 126, p. 24-29, 2016. Disponível em: http:/ / www.funcex.org.br/publicacoes/rbce/ material/rbce/126_CACL.pdf Acesso em 29/08/2016.

LOPEZ, José Manuel Cortiñas; GAMA, Marilza. Comércio Exterior Competitivo. 2. ed. São Paulo: Aduaneiras, 2002.

LÓPEZ, Andrés; NIEMBRO, Andrés; RAMOS, Daniela. O Comércio Mundial De Serviços. Revista Brasileira de Comércio Exterior, n. 106, p. 6-18, 2011. Disponível em: http://www.funcex.org.br/publicacoes/rbce/material/rbce/106_ALANDR.pdf. Acesso em 29/08/2016.

MELO, Hildete Pereira de; ROCHA, Carlos Frederico Leão; FERRAZ, Galeno; DI SABBATO, Alberto; DWECK, Ruth Helena. É Possível uma Política Para o Setor Serviços? Diretoria de Pesquisa do IPEA. 1997. 
MINISTÉRIO DO DESENVOLVIMENTO, INDÚSTRIA E COMÉRCIO EXTERIOR (MDIC). Serviços, Panorama do Comércio Internacional 2013 (Dados consolidados de 2012). 2013.

. Guia Básico para Exportação de Serviços. 2014a.

Serviços, Panorama do Comércio Internacional 2014. 2014b.

Serviços 2015, Panorama do Comércio Internacional. 2016a.

PEREIRA, Lia Valls. Exportações de Serviços Comerciais Brasileiros: Desafios para a Formulação de uma Política Comercial. BNDES, 2002. Disponível em: http:/ /www. bndespar.gov.br/SiteBNDES/export/sites/default/bndes_pt/Galerias/Arquivos/ conhecimento/livro_desafio/Relatorio-12.pdf. Acesso em 04/09/2016.

PEREIRA, Lia Valls; SENNES Ricardo; MULDER; Nanno. Exportações Brasileiras de Serviços Comerciais. Revista Brasileira de Comércio Exterior, n. 106, 2011. Disponível em: http://www.funcex.org.br/publicacoes/rbce/material/rbce/106_LVPRSNM. pdf. Acesso em 29/08/2016.

PEREIRA, Vinícius Rena. O setor serviços no Brasil. Universidade Estadual Paulista (UNESP) "Júlio de Mesquita Filho", Faculdade de ciências e letras Campus de Araraquara - SP, 2014.

PORTAL BRASIL. Governo Lança Portal Brasileiro de Comércio Exterior. 2011. Disponível em: http:/ /www.brasil.gov.br/governo/2011/08/governo-lanca-portalbrasileiro-de-comercio-exterior. Acesso em 01/10/2015.

. Registro de importação e exportação de serviços será exigido a partir de agosto. 2012a. Disponível em: http:/ / www.brasil.gov.br/economia-eemprego/2012/07/registro-em-importacao-e-exportacao-de-servicos-serao-exigidosa-partir-de-agosto. Acesso em 03/10/15.

. Entra em vigor sistema de registro de importação e exportação. $2012 b$.

Disponível em: http:/ / www.brasil.gov.br/economia-e-emprego/2012/08/entra-emvigor-sistema-de-registro-de-importacao-e-exportacao. Acesso em 03/10/15.

PORTAL DA COPA. Governo Federal, FIFA e CBF apresentam legados da Copa do Mundo de 2014. 2015. Disponível em: http: / / www.copa2014.gov.br/pt-br/noticia/ governo-federal-fifa-e-cbf-apresentam-legados-da-copa-do-mundo-de-2014. Acesso em $22 / 10 / 2016$.

PORTER, Michael E.. Competição: estratégias competitivas essenciais. 4. ed. Rio de Janeiro: Campus, 1999.

RIBEIRO, Fernando. Brasil precisa dar maior importância ao comércio exterior de serviços. Revista Brasileira de Comércio Exterior, n.106, 2011. Disponível em: http:/ / www.funcex.org.br/publicacoes/rbce/material/rbce/106-EDITORIAL.pdf. Acesso em 29/08/2016. 
SCHMENNER, Roger W.; PERES, Lenke. Administração de operações em serviços. São Paulo: Futura, 1999.

STEFANO, Fabiane; Revista EXAME. A Lava-Jato agora é internacional. 2016.

Disponível em: http:/ / exame.abril.com.br/revista-exame/edicoes/1111/noticias/alava-jato-agora-e-internacional. Acesso em 26/09/2016.

UNITED NATIONS CONFERENCE ON TRADE AND DEVELOPMENT (UNCTAD). Trade in Services 2015. 2016. Disponível em: http:/ / unctadstat.unctad.org/EN/ Infographics.html\#\&gid=2016\&pid=Trade $\% 20 \mathrm{in} \% 20$ services $\% 20 \mathrm{in} \% 202015$. Acesso em 16/09/2016.

Statistics. Goods and services (BPM6): Trade openness indicators, annual, 2005-2014. 2015. Texto Digital. Disponível em: http://unctad.org/en/Pages/Home. aspx. Acesso em 01/09/2016.

WORLD TRADE ORGANIZATION (OMC). Trade in commercial services.

Disponível em: https://www.wto.org/english/res_e/statis_e/tradeserv_stat_e.htm. Acesso em: 01/04/17. 